\title{
New Australian Utricularia taXa PUBLISHED SINCE ALLEN LOWRIE's MAGNUM OpUS
}

RiCHARD NUNN • Sydney • Australia • richardjnunn1@gmail.com

At the time of completion of Magnum Opus by the end of 2013, the genus Utricularia L. (Lentibulariaceae) contained approximately 240 monographed species worldwide (Taylor 1989, Fleischmann 2012, 2015, Lowrie 2014), with 66 of these found in Australia (Lowrie 2014). The genus is divided into the three subgenera Polypompholyx, Bivalvaria, and Utricularia (sensu Müller $\&$ Borsch 2005) with Lowrie's Australian roster recognising 40 species in subgenus Polypompholyx, 15 species in subgenus Bivalvaria and 11 in subgenus Utricularia.

Since Magnum Opus, there has been much further study of Australian Utricularia lead by Australian Botanist, Richard Jobson, of the Royal Botanic Garden Sydney, (Jobson 2013, Jobson \& Baleeiro 2015, 2020, Jobson et al. 2018, Jobson \& Cherry 2020, Jobson \& Davies-Colley 2020), adding a further 21 new species and subspecies to Lowrie's roster of Australian Utricularia. Two have been resurrected, one species, Utricularia monanthos Hook.f. (= U. dichotoma subsp monanthos (Hook.f.) R.W.Jobson) has been revised and U. corneliana R.W.Jobson has been reduced to synonomy with $U$. reflexa Oliv.(Fleischmann 2015), leaving a total of 88 currently recognised taxa found in Australia.

This paper will provide a brief treatment of the newly described and reinstated Australian Utricularia species and subspecies since Lowrie's seminal work, Carnivorous Plants of Australia, Magnum Opus (Lowrie 2014).

Utricularia adamsii R.W.Jobson \& Davies-Colley 2020

Small perennial, suspended or affixed aquatic herb (Fig. 1). The specific epithet honours Laurence George Adams (1929-2014), a researcher at the Australian National Herbarium, who in March 1967 collected the first known specimen of $U$. adamsii near Darwin, Northern Territory. Known only from four locations, one on Cape York and three sites near Darwin (Fig. 1). Similar to U. aurea Lour., but differs in shape and length of rhizoid float appendages (20-30 mm v. 50-100 mm long), corolla spur always glabrous and longer than the corolla lower lip v. spur hairy and shorter or equal in length to the corolla lower lip.

\section{Utricularia albertiana R.W.Jobson \& Baleeiro 2018}

Small annual, affixed subaquatic herb (Figs. 2 \& 24). The specific epithet honours Prof. Victor A. Albert, botanist and evolutionary biologist in the Department of Biological Sciences at the University at Buffalo, State University of New York, who has contributed immensely to our understanding of the genus Utricularia. Known from three locations in the Northern Kimberley region, Western Australia. Found growing in shallow pools on sandstone pavement and outcrops. Previously confused with $U$. dunstaniae F.E.Lloyd from the Northern Territory and differs in having spur apex rounded/obtuse, central corolla lower lip lobe longer than the spur, calyx lower lip almost as long as the spur, and trap dorsal appendage usually present. 


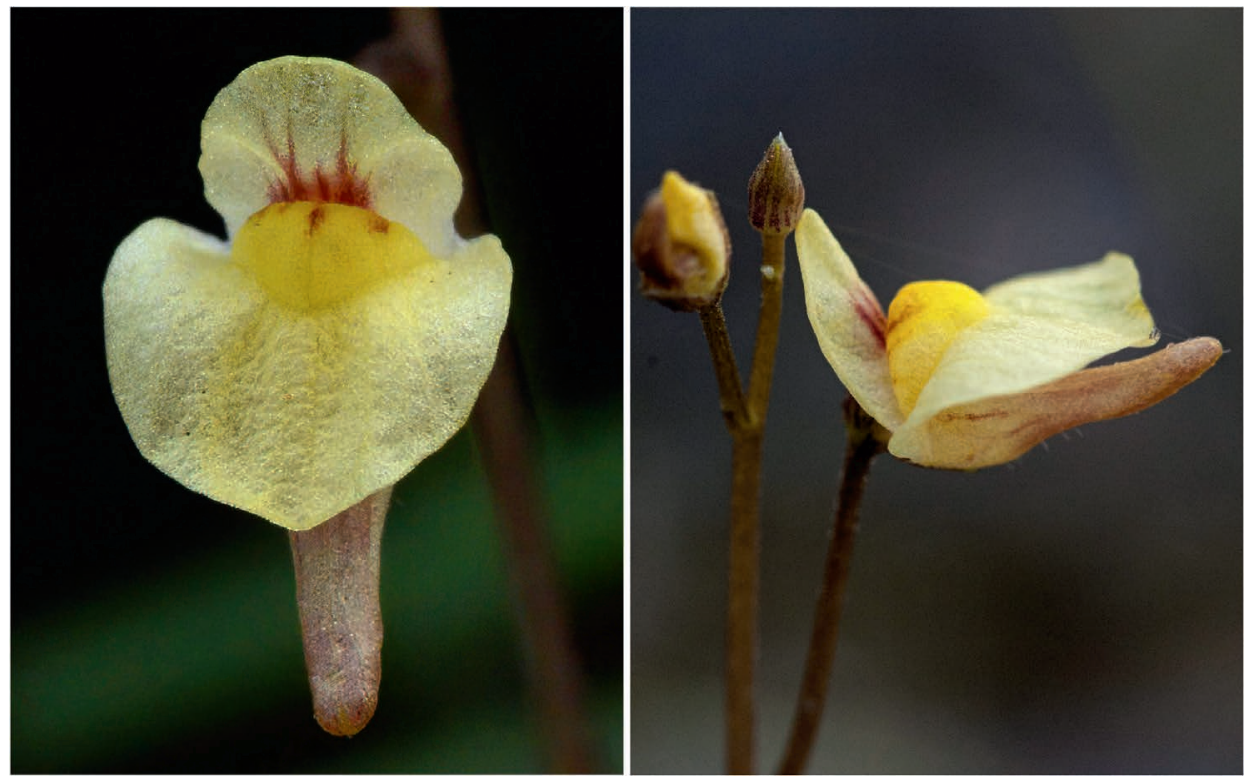

Figure 1: Utricularia adamsii flower frontal view (image R. Nunn); flower lateral view (image G. Bourke).

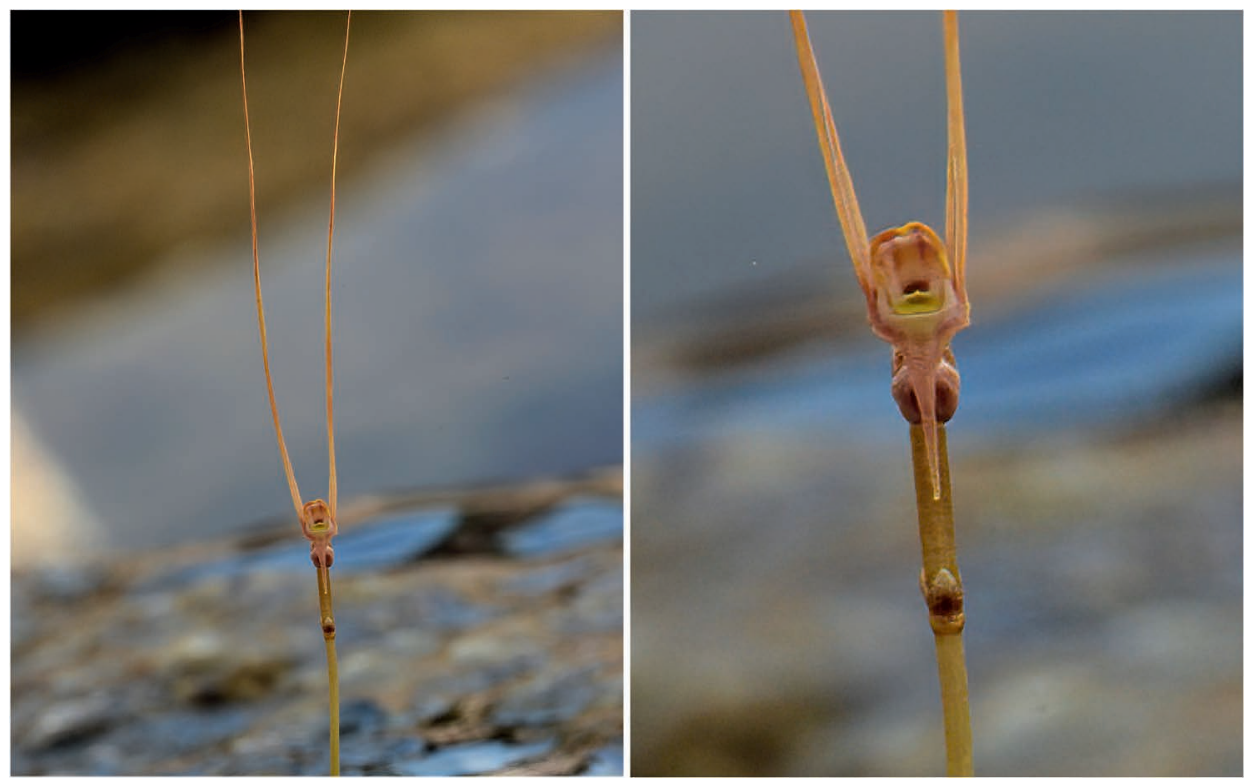

Figure 2: Utricularia albertiana flower frontal view (image R. Nunn); closeup view of same flower. 
Utricularia ameliae R.W.Jobson 2013

Small perennial, terrestrial herb (Fig. 3). The specific epithet refers to Miss Amelia Pieternella Jobson, daughter of the author of this species, Richard Jobson. Only found in Elizabeth Springs, Queensland, situated in the Diamantina River Catchment on the flood-plain of Spring Creek. Elizabeth Springs forms part of the Springvale group of artesian discharge springs. Colonies of Utricularia ameliae are scattered throughout the permanently wet sedgeland bog habitat. This species differs from $U$. dichotoma Labill. with presence of bracts and bracteoles that are basally non-gibbous; spur tapers to an acutely bifid apex; white corolla upper lip.

Utricularia barkeri R.W.Jobson 2013

Small to medium-sized perennial, terrestrial herb (Fig. 4). The specific epithet refers to Dr William (Bill) R. Barker, former Chief Botanist of the State Herbarium of South Australia (AD), who has made significant contributions to Australian botany with studies of Australasian Scrophulariaceae and various other families. Distributed on flat coastal areas of South Australia, Victoria, and west coast of Tasmania, usually at or near sea level. Utricularia barkeri occupies coastal ephemeral sedge swampland and heath soakage on deep sand. This species differs from U. dichotoma with presence of basiolute bracts with upper and lower lobes of \pm equal length; corolla upper lip light mauve with purple flecks.

Utricularia beaugleholei subsp. orientalis R.W.Jobson 2020

Small to medium-sized perennial, terrestrial herb, stolon tubers often present (Fig. 5). The subspecific epithet is from the Latin orientalis (of the east) and refers to the mostly eastern geographic distribution relative to subsp. beaugleholei. Distributed in the Eastern Highlands and Riverina regions of Victoria, extending onto the South-Western Slopes and Southern Tablelands of New South Wales. Occurs in sand and clay along seasonally wet creeks and farm dam soaks, and in nearby grasslands and pasture. Utricularia beaugleholei subsp. orientalis resembles the larger subspecies of $U$. dichotoma in overall size and shape of flowers, and Taylor's (1989) use of Darbyshire 514 (a specimen of $U$. beaugleholei subsp. orientalis) for floral illustration of $U$. dichotoma has led to confusion in the field.

\section{Utricularia bidentata R.W.Jobson \& Baleeiro 2018}

Small to medium-sized probably annual, terrestrial herb (Fig. 6). The specific name is from the Latin bi- (two) and dentatus (toothed) and refers to the two white, prominently raised ridges that project forward from the palate resembling two sharp teeth. Widespread across the Kimberley region from Broome to Mitchell Plateau, Western Australia, with localised disjunct occurrences at Nitmiluk, Northern Territory. Although the disjunction between Western Australia and Northern Territory populations involves $\sim 800 \mathrm{~km}$, habitat is similar, with plants infrequent along edges of rocky or sandy creeks, among grasses and sedges. This species was previously confused with Utricularia kimberleyensis C.A.Gardner with the differences involving colour of the palate spot (yellow / orange vs cream), and size of the two central ridges at the base of the corolla lower lip (not raised relative to adjacent ridges vs prominently raised relative to adjacent ridges). The two species tend to differ in habitat, with $U$. bidentata often occurring on soils with a high clay content, including cracking clay plains, while U. kimberleyensis typically grows in alluvial silt on sand flats derived from sandstone. 


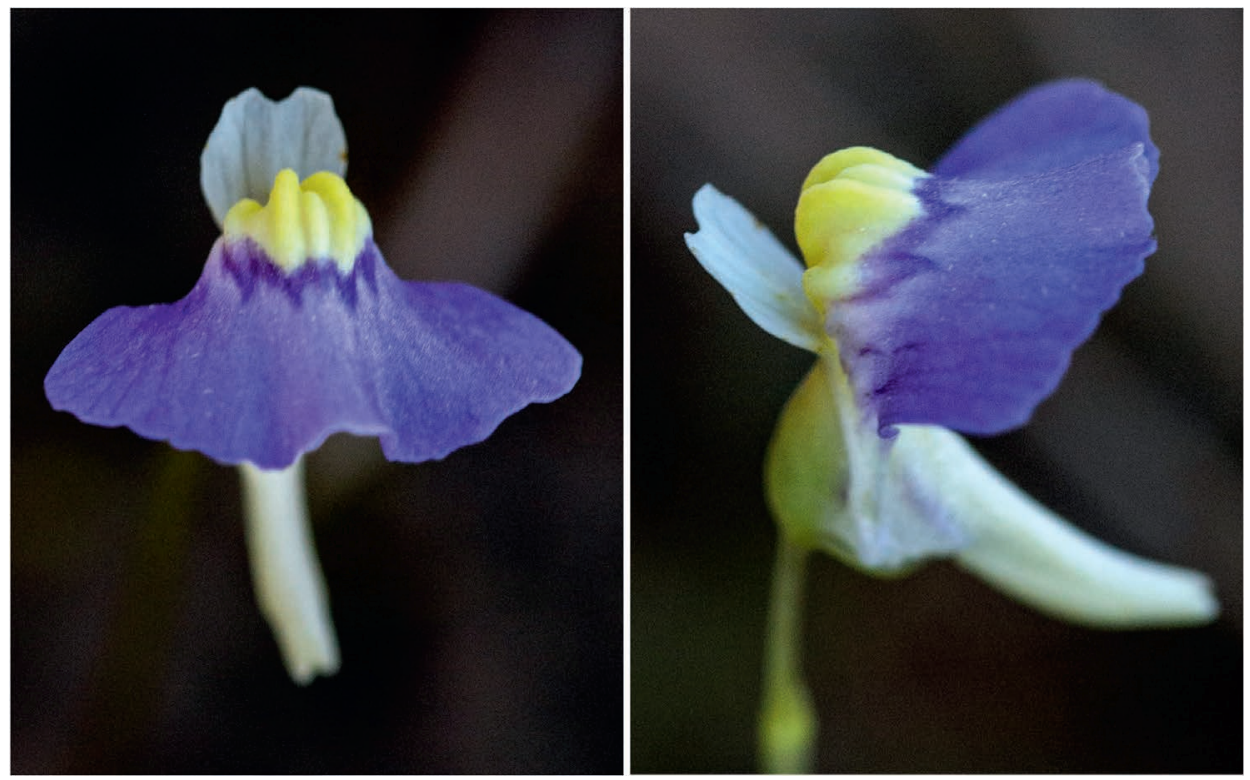

Figure 3: Utricularia ameliae flower frontal view; flower lateral view (images G. Bourke).
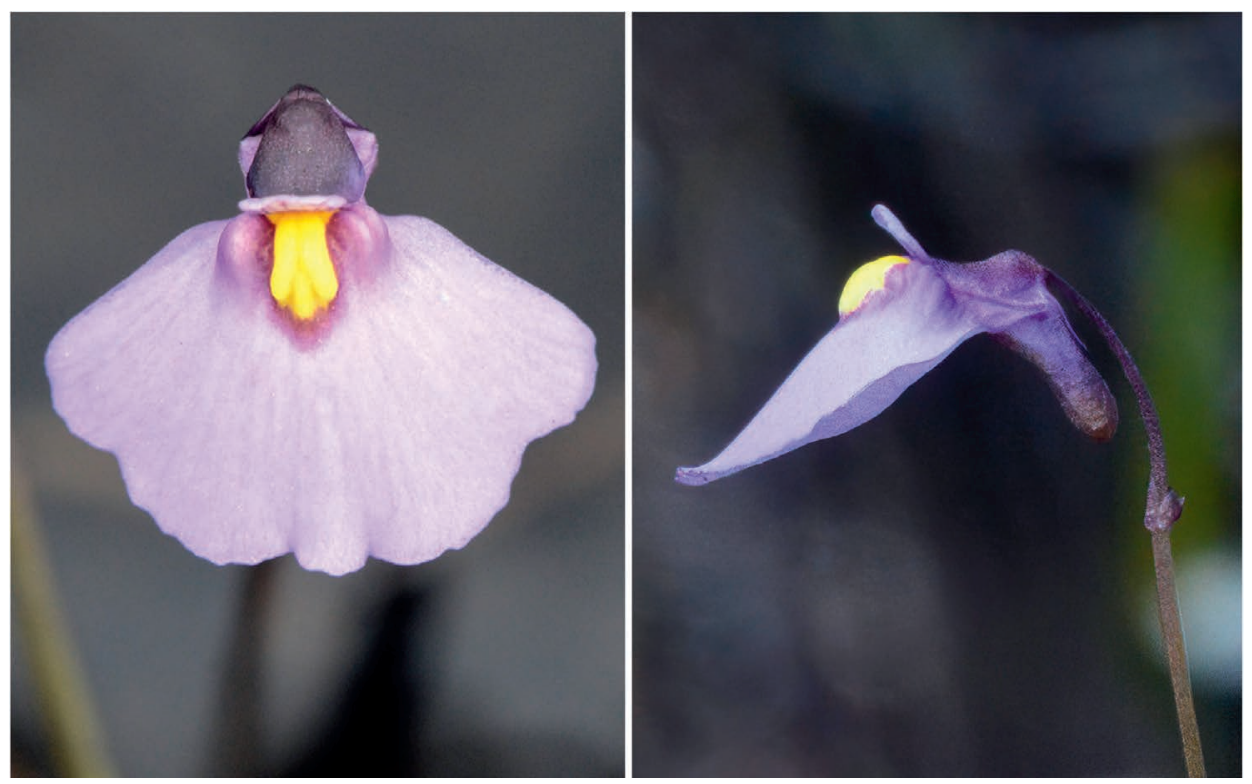

Figure 4: Utricularia barkeri flower frontal view (image R. Nunn); flower lateral view (image D. Cullen). 


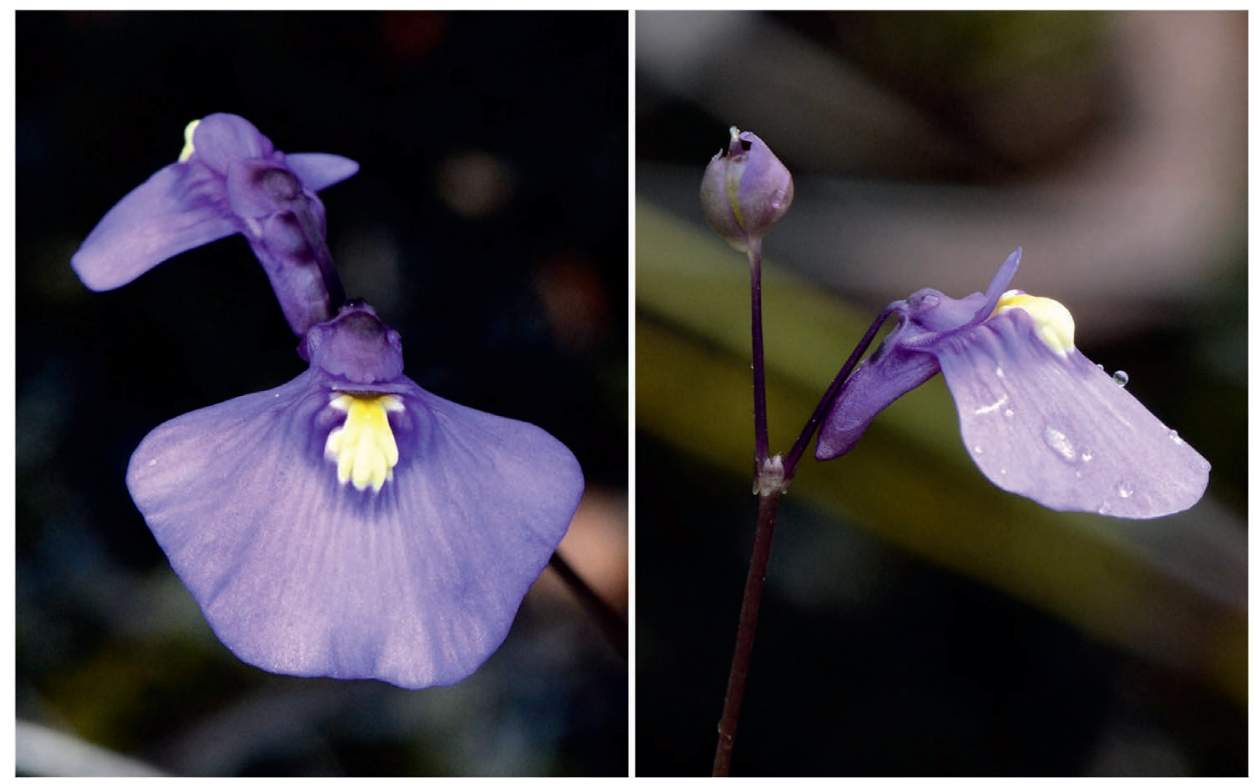

Figure 5: Utricularia beaugleholei subsp. orientalis flower frontal view; flower lateral view (images R. Nunn).

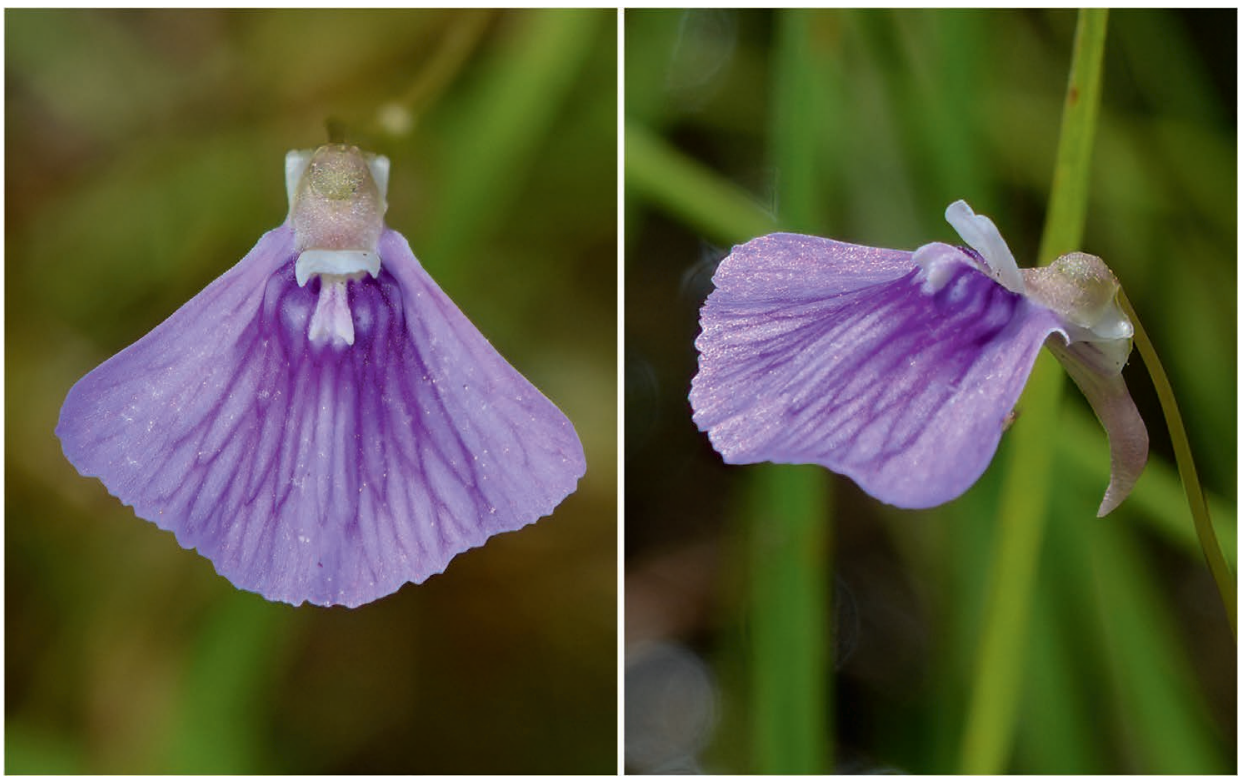

Figure 6: Utricularia bidentata flower frontal view; flower lateral view (images T. Krueger). 


\section{Utricularia byrneana R.W.Jobson \& Baleeiro 2015}

Small to medium-sized perennial, terrestrial herb (Fig. 7). The specific epithet honours Dr Geoff Byrne who recognised the uniqueness of this species and made the first known collection of Utricularia byrneana. Recorded from two swamps in Western Australia on the Dampier Peninsula, separated by approximately $100 \mathrm{~km}$. This species is locally common inhabiting shallow edges of ephemerally wet swamps and lagoons. Similar to U. fistulosa P.Taylor, but differs in having leaves lanceolate, corolla mauve with two raised yellow ridges at base, corolla spur cylindrical, apex rounded, shorter than lower lip, seeds cylindrical, trap dorsal appendage short.

\section{Utricularia dichotoma subsp. aquilonia R.W.Jobson 2020}

Terrestrial perennial herb (Fig. 8). The subspecific epithet is from the Latin aquilonius (north, northerly) and refers to the mostly North Coast and Northern Tablelands geographic distribution. Known only from New South Wales, where it is found in upland swamps and creeks of the Central and Northern Tablelands and heathland swamps of the North Coast. Distinguished from Utricularia dichotoma by the bracts and bracteoles that are strongly gibbous versus spurred.

\section{Utricularia dichotoma subsp. fontana R.W.Jobson 2020}

Terrestrial perennial or annual herb (Fig. 9). The subspecific epithet is from the Latin fontanus (of a spring or fountain), alluding to the habitat of most known populations. Occurs in central Queensland in recharge springs of the Great Artesian Basin and in mountain creeks and springs of the Blackdown Tablelands, in the Moreton region where it is found in ephemerally wet coastal creek gullies in open woodland, and in New South Wales where it is found in semipermanent springs along creeks of the North Western Slopes and Northern Tablelands. Differs from other members of the Utricularia dichotoma complex by the corolla spur which is curved forward near the apex and is longer than the corolla lower lip. This long, forward-curved spur is conspicuous and consistent.

\section{Utricularia dichotoma subsp. maritima R.W.Jobson 2020}

Terrestrial perennial herb (Fig. 10). The subspecific epithet is from the Latin maritimus (of the sea), referring to the usually coastal habitat and distribution. Widespread from the Darling Downs of Queensland, south to Victoria and Tasmania and west as far as Kangaroo Island in South Australia. Found mostly in heathy swamps and associated creeks on coastal slopes and plains. Can be discriminated from all other subspecies of Utricularia dichotoma in having an apically acute basal spur on the bracts and bracteoles versus either spur-less or spur apically rounded or truncate.

\section{Utricularia dichotoma subsp. novae-angliae R.W.Jobson 2020}

Emergent aquatic annual herb (Figs. $11 \& 25$ ). The subspecific epithet is from the Latin nova (new), and Anglia (England), referring to its distribution in the New England Bioregion of the Northern Tablelands of New South Wales. Occurs in shallow, semi-permanent montane swamps over clay loam on basalt substrates between Uralla and Llangothlin on the Northern Tablelands of New South Wales. This taxon differs from all other subspecies of Utricularia dichotoma having an emergent habit, long, linear leaves, and a conical corolla spur that is less than half the length of the lower lip.

\section{Utricularia dichotoma subsp. oxleyensis R.W.Jobson 2020}

Terrestrial perennial herb (Fig. 12). The subspecific epithet refers to the Oxley Wild Rivers National Park located in the Northern Tablelands region of New South Wales. Known only from four 
sites between Ebor and the Carrai Plateauin the Oxley Wild Rivers National Park, New South Wales. Occurs in seasonally moist heathy swamps on peatysubstrate, at 880-1500 m altitude. This taxon differs from all other subspecies of Utricularia dichotoma having a terrestrial habit, small, ovate leaves, a straight corolla spur, and distinctly hatchet-shaped corolla lower lip.
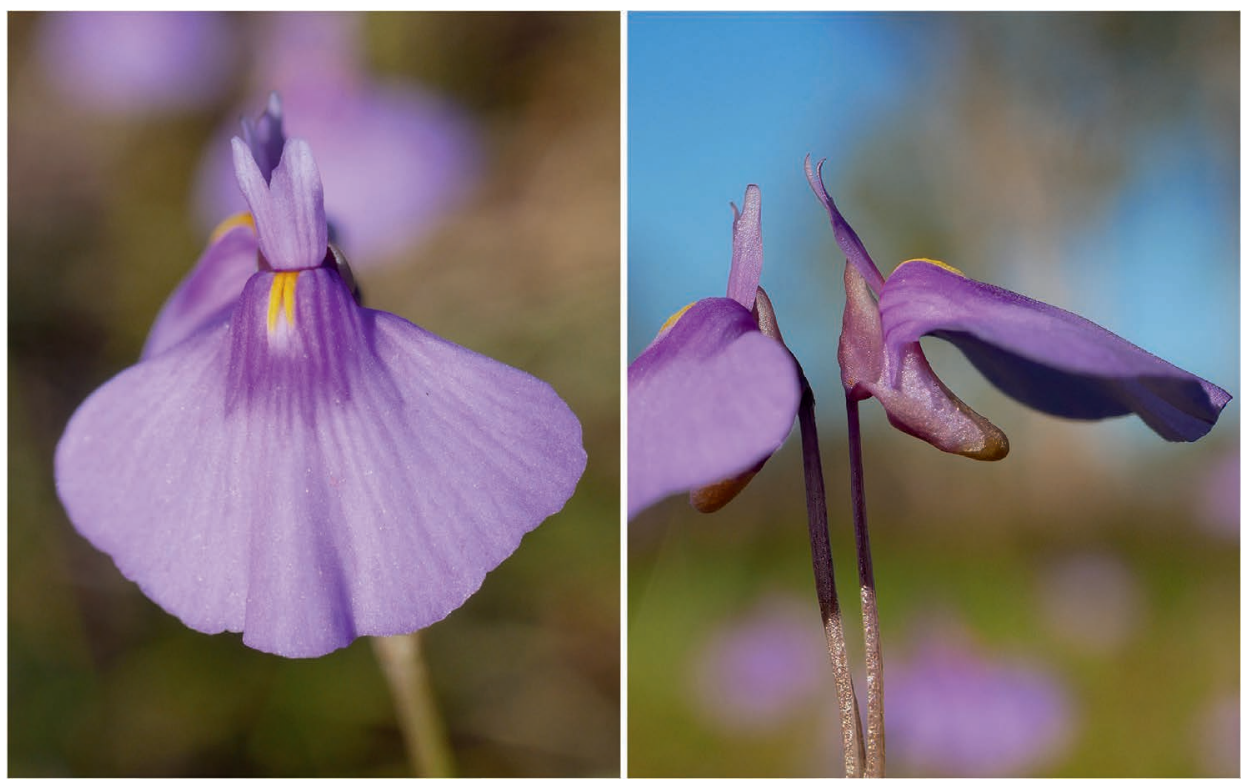

Figure 7: Utricularia byrneana flower frontal view; flower lateral view (images T. Krueger).
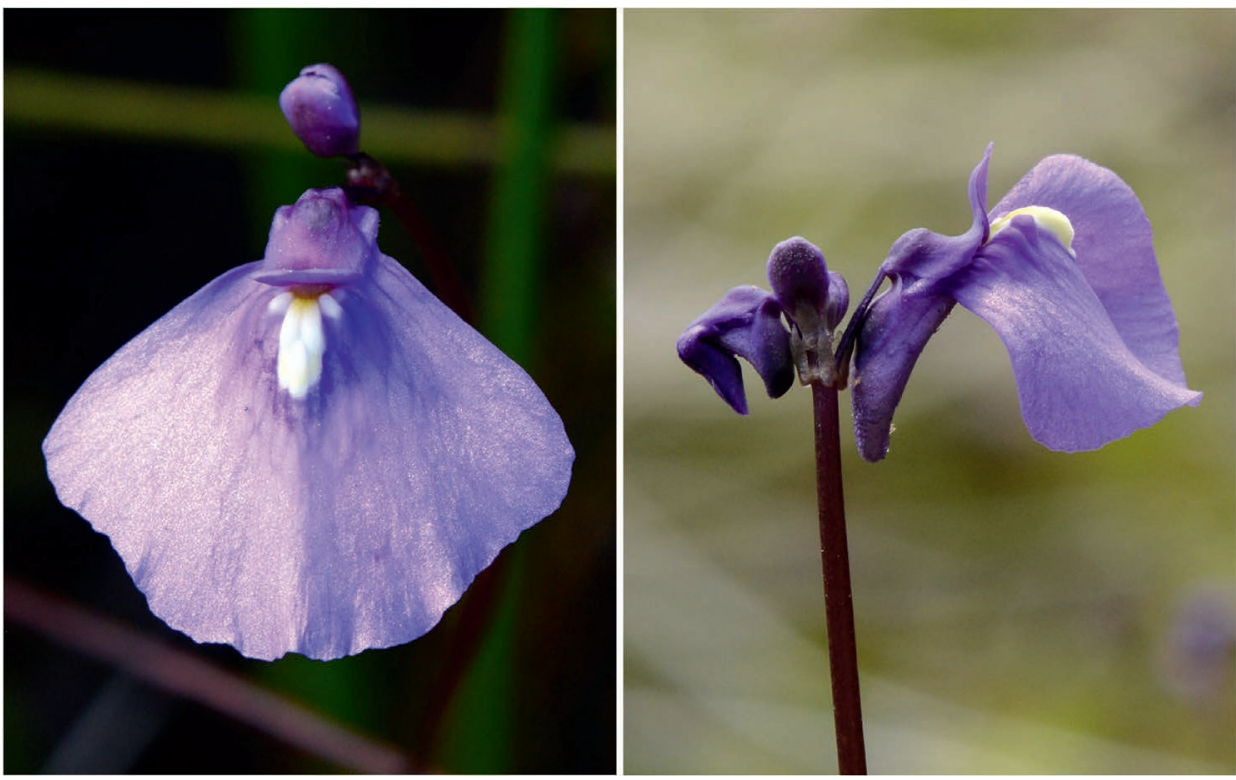

Figure 8: Utricularia dichotoma subsp. aquilonia flower frontal view; flower lateral view (images R. Nunn). 


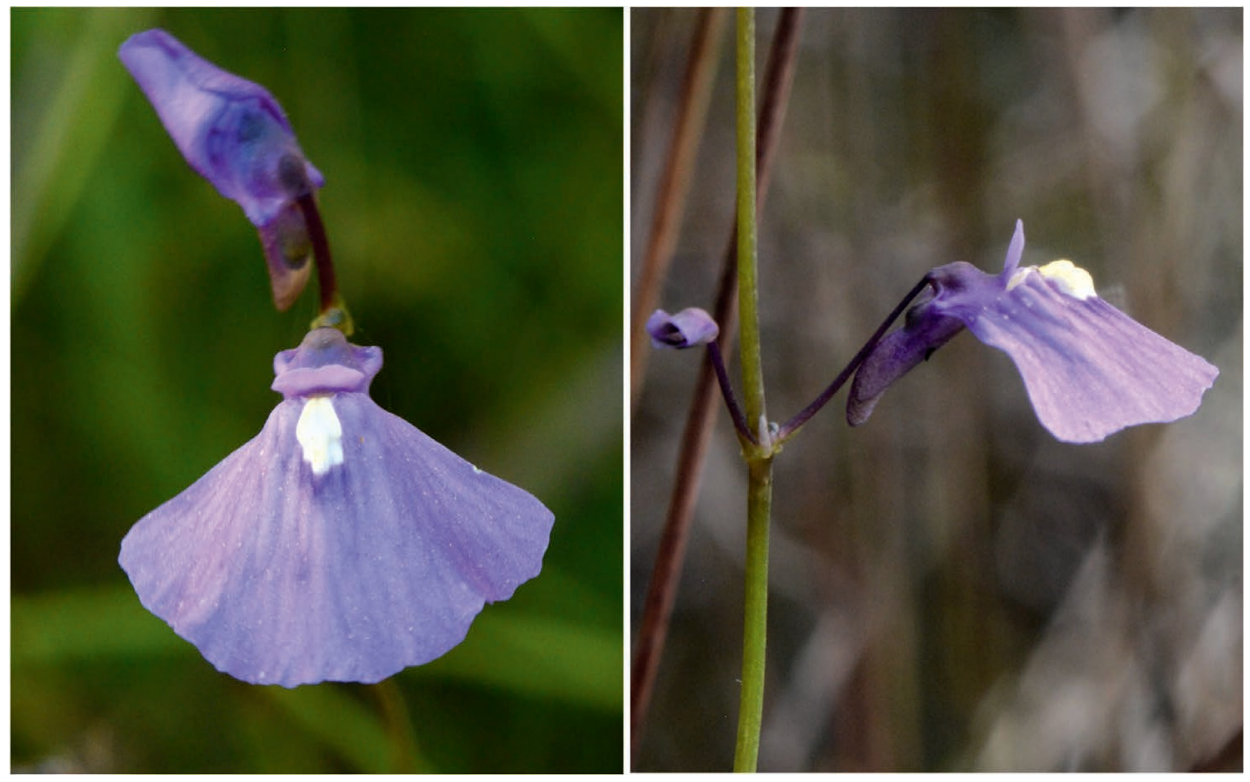

Figure 9: Utricularia dichotoma subsp. fontana flower frontal view; flower lateral view (images R. Nunn).

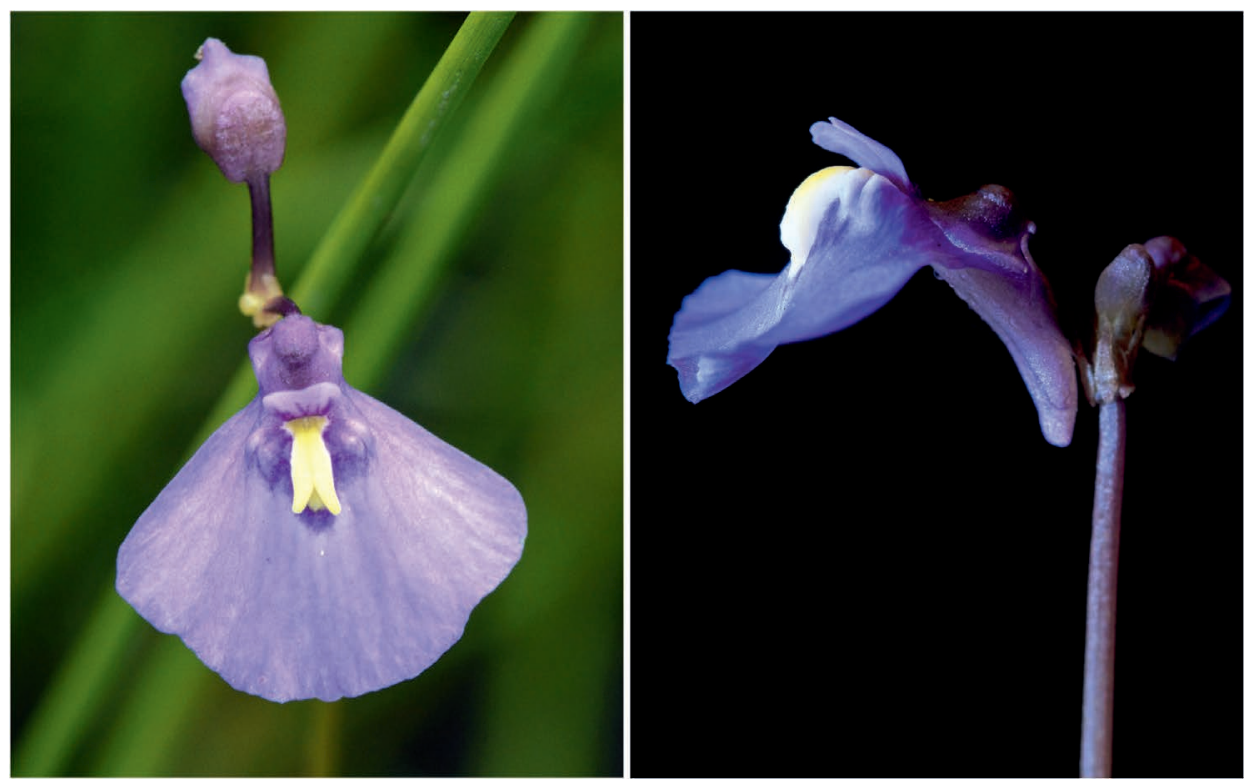

Figure 10: Utricularia dichotoma subsp. maritima flower frontal view (image R. Nunn); flower lateral view (image G. Bourke). 

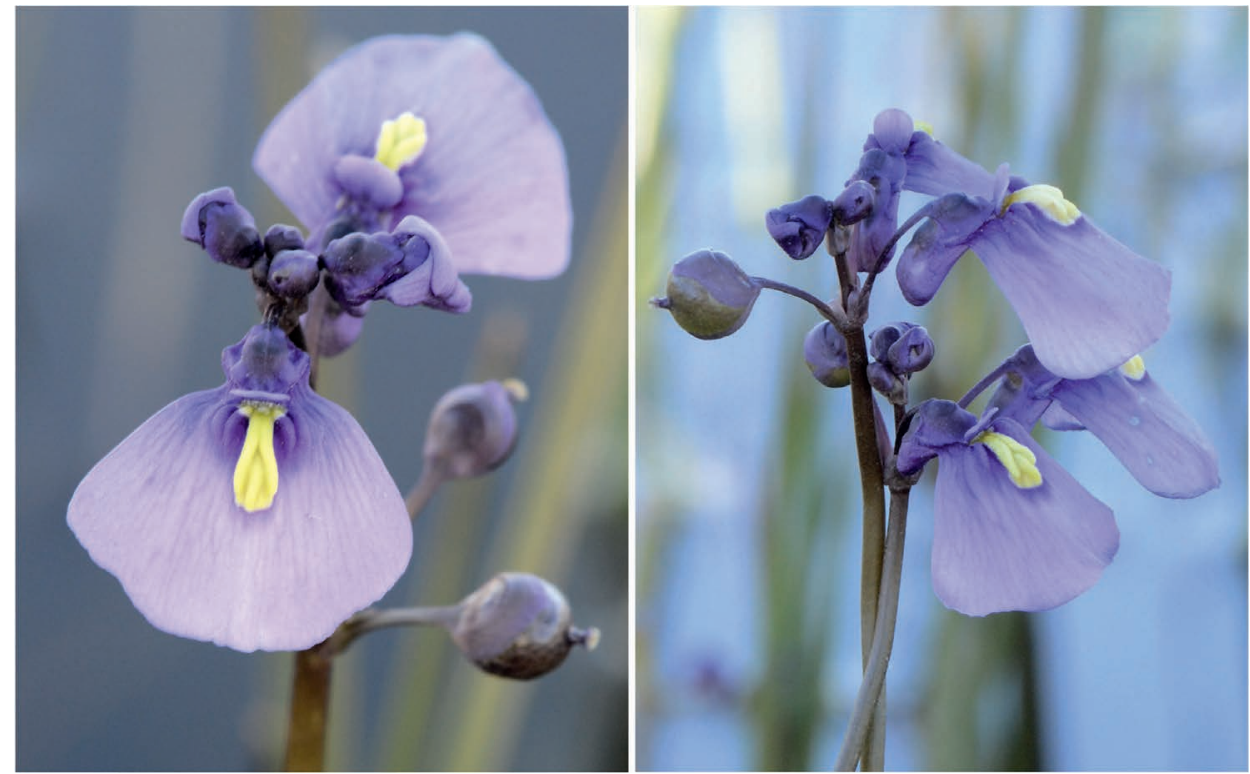

Figure 11: Utricularia dichotoma subsp. novae-angliae flower frontal view; flower lateral view (images R. Nunn).
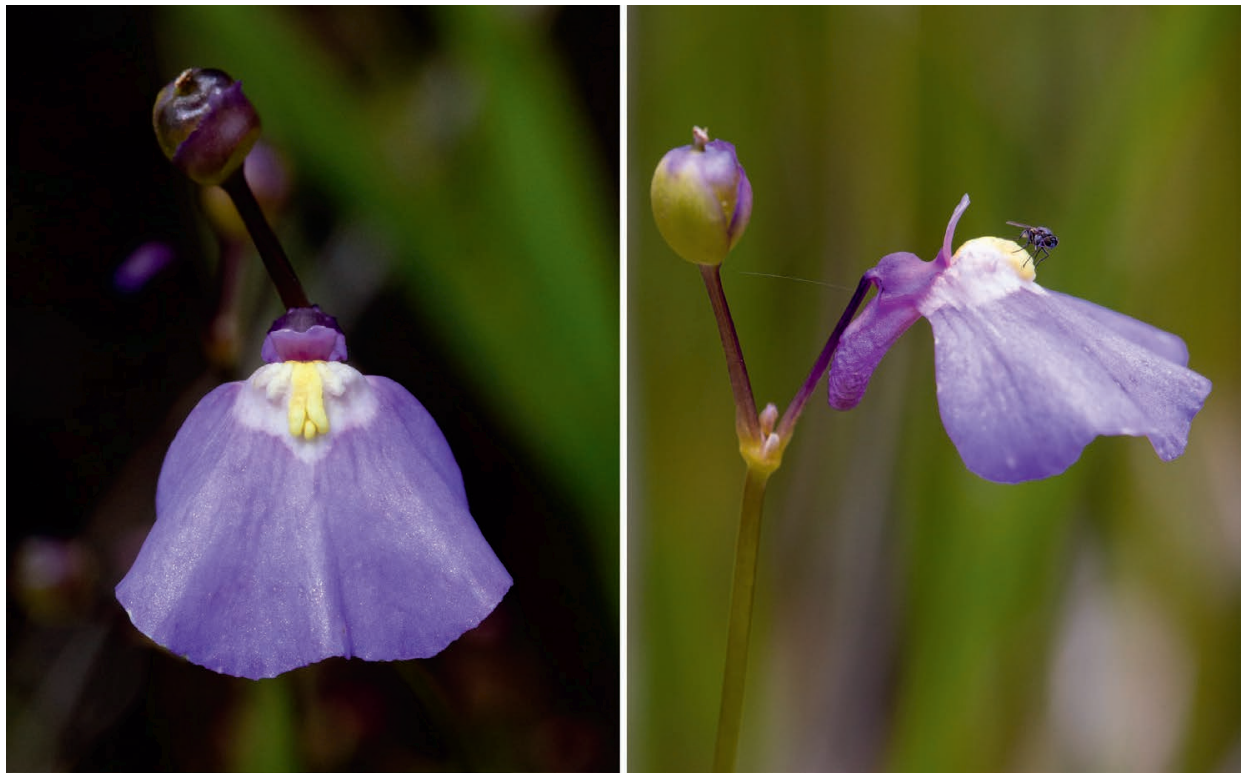

Figure 12: Putative Utricularia dichotoma subsp. oxleyensis flower frontal view; flower lateral view. The plant's location and floral characters strongly support this diagnosis; however, this is a poorly known subspecies (images Greg Bourke). 


\section{Utricularia fenshamii R.W.Jobson 2013}

Small to medium-sized perennial, terrestrial herb (Fig. 13). The specific epithet refers to Associate Prof. Roderick Fensham of the School of Biological Sciences, The University of Queensland, and the Queensland Herbarium, who has contributed greatly to our knowledge of the biology and ecology of the mound springs distributed across the Great Artesian Basin. This species is restricted to wetlands associated with discharge mound springs across the Great Artesian Basin. A specimen of this taxa was collected by C.W. Burgh de Birch (circa 1871) and was sent to Ferdinand von Mueller as "Utricularia" sp. until determined as U. dichotoma by Peter Taylor in 1985. This species differs from $U$. dichotoma with presence of bracts and bracteoles that are basally non-gibbous; corolla lower lip central ridge twice the length of neighbouring ridges.

\section{Utricularia gaagudju R.W.Jobson \& Cherry 2020}

Medium-sized, probably annual, terrestrial herb (Fig. 14). The specific epithet is a noun in apposition that refers to the Aboriginal language Gaagudju formerly spoken in Arnhem Land, in the vicinity, and the namesake of, Kakadu National Park. Found in the Northern Territory from Pine Creek to Jabiru, Daly Basin, and Darwin region. Also collected on Bathurst and Melville Islands. Grows in silty areas near boggy creeks with sedges and grasses. Utricularia gaagudju was previously confused with $U$. kimberleyensis, with the key difference involving colour of the corolla (light purple v. mauve), the margin of corolla lower lip (entire v. slightly three-lobed), the raised central palate ridges (yellow v. orange) the corolla spur (curved forward v. straight), and the peduncle (basal third hispid v. glabrous).

\section{Utricularia grampiana R.W.Jobson 2013}

Small to medium-sized probably annual, terrestrial herb (Fig. 15). The specific epithet refers to the Grampians National Park (Gariwerd) located in Victoria's western highland region. Within Victoria, Utricularia grampiana has a restricted distribution, all recorded collections represent populations protected within the Grampians National Park and Langi Ghiran State Park. Thus far restricted to high elevation (alt. 400-1170 m) on sandstone seepages in the Mt Difficult and Mt William Ranges within the Grampians National Park (Gariwerd), and in similar habitat at Mt Langi Ghiran. Usually forms small colonies among mosses and sedges in seepage areas on rock platforms. This species differs from $U$. dichotoma with presence of basiolute bracts with upper lobes about twice the length of lower; corolla upper lip cream with purple flecks.

\section{Utricularia hamata R.W.Jobson \& M.D.Barrett 2018}

Small to medium sized possibly perennial, terrestrial or affixed subaquatic herb (Fig. 16). The specific epithet is from the Latin hamatus (shaped like a hook, hooked, crooked) and refers to the deflexing of the peduncle post anthesis. Known from only three sites in the Kimberley, Western Australia. In the north Kimberley (type location) it grows either as an emergent in deep pools of creek-line $(20-30 \mathrm{~cm})$ with sandstone substrate, or as a terrestrial on shallow sandy edges. At the Harding Range in the West Kimberley, it was found in a shallow creek on a sandstone pavement. In the Central Kimberley it was found growing within a herb field flat with Melaleuca viridiflora, in a wetland/chute area, with red-brown to dark brown clayey soil. Similar to Utricularia hamiltonii F.E.Lloyd but differs in having bifid lateral trap appendages, a white corolla, 2-lobes of upper lip limb rounded, corolla lower lip limb obovate, spur broadly conical, curved upwards with apex yellow. 


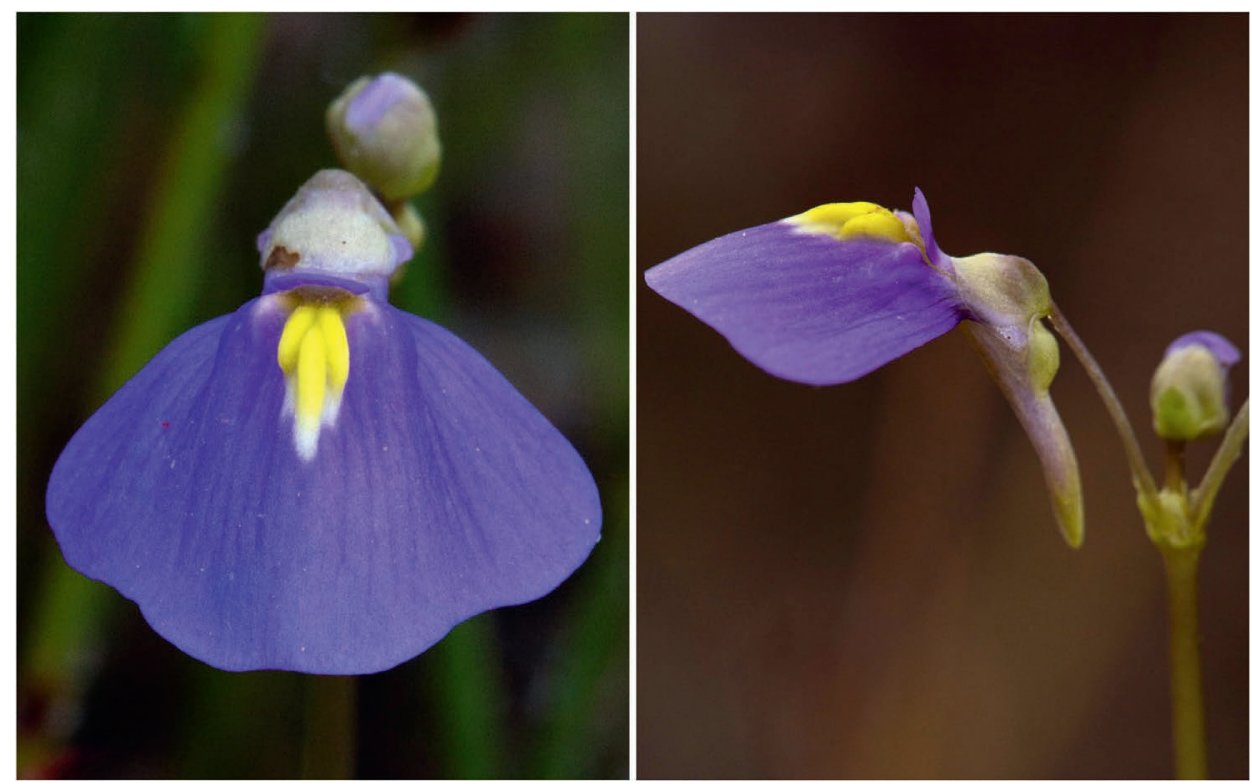

Figure 13: Utricularia fenshamii flower frontal view; flower lateral view (images G. Bourke).
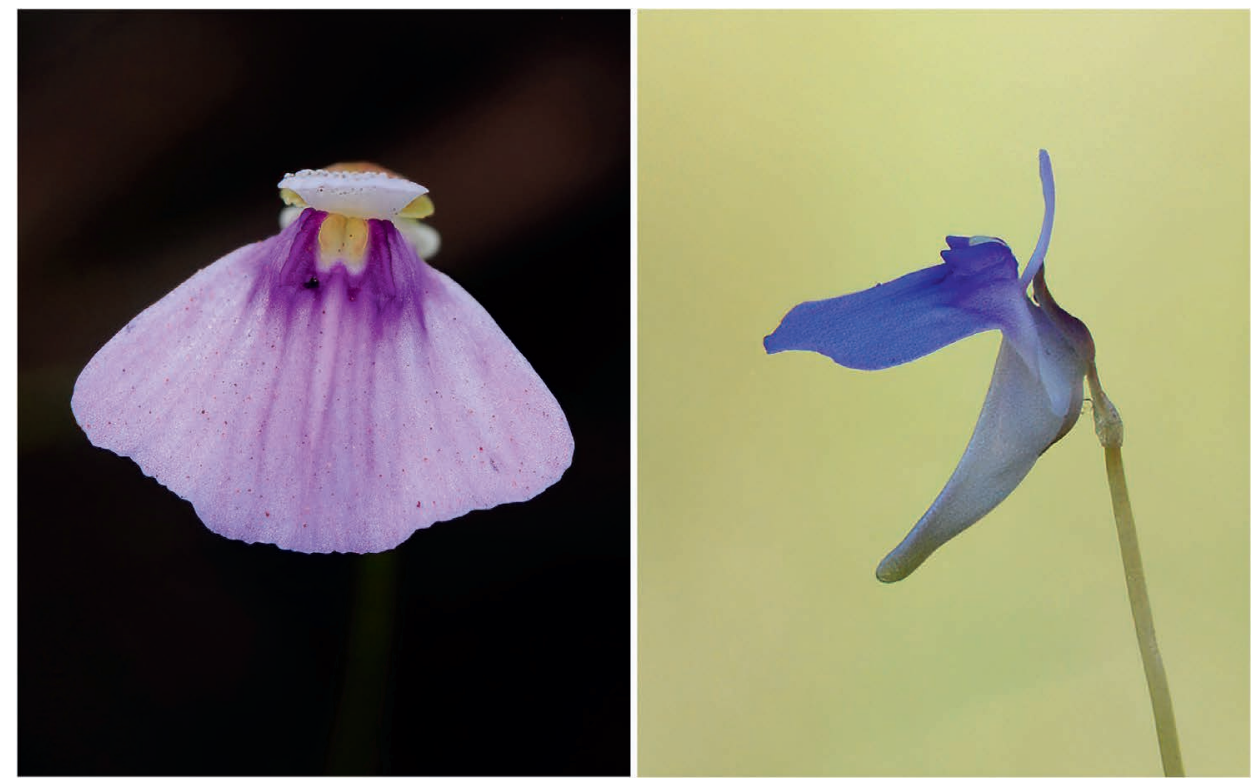

Figure 14: Utricularia gaagudju flower frontal view; flower lateral view (images R. Nunn). 


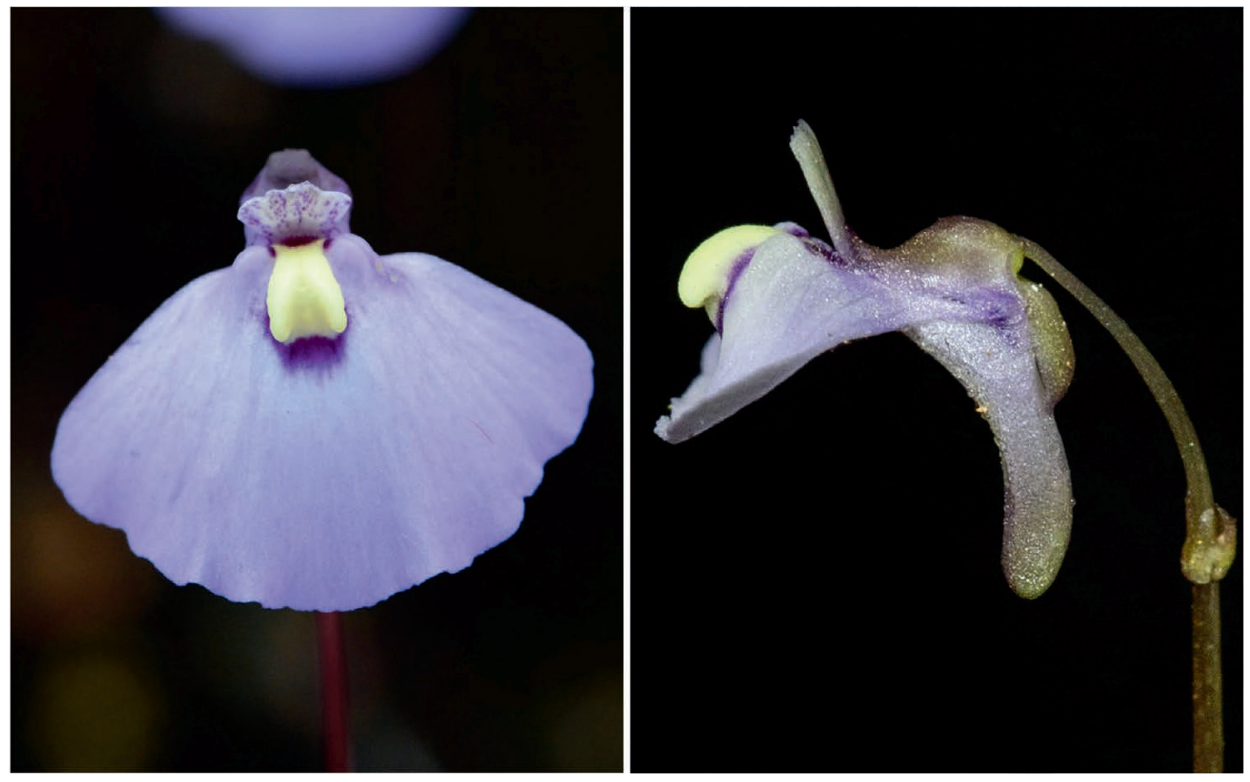

Figure 15: Utricularia grampiana flower frontal view (image R. Nunn); flower lateral view (image G. Bourke).

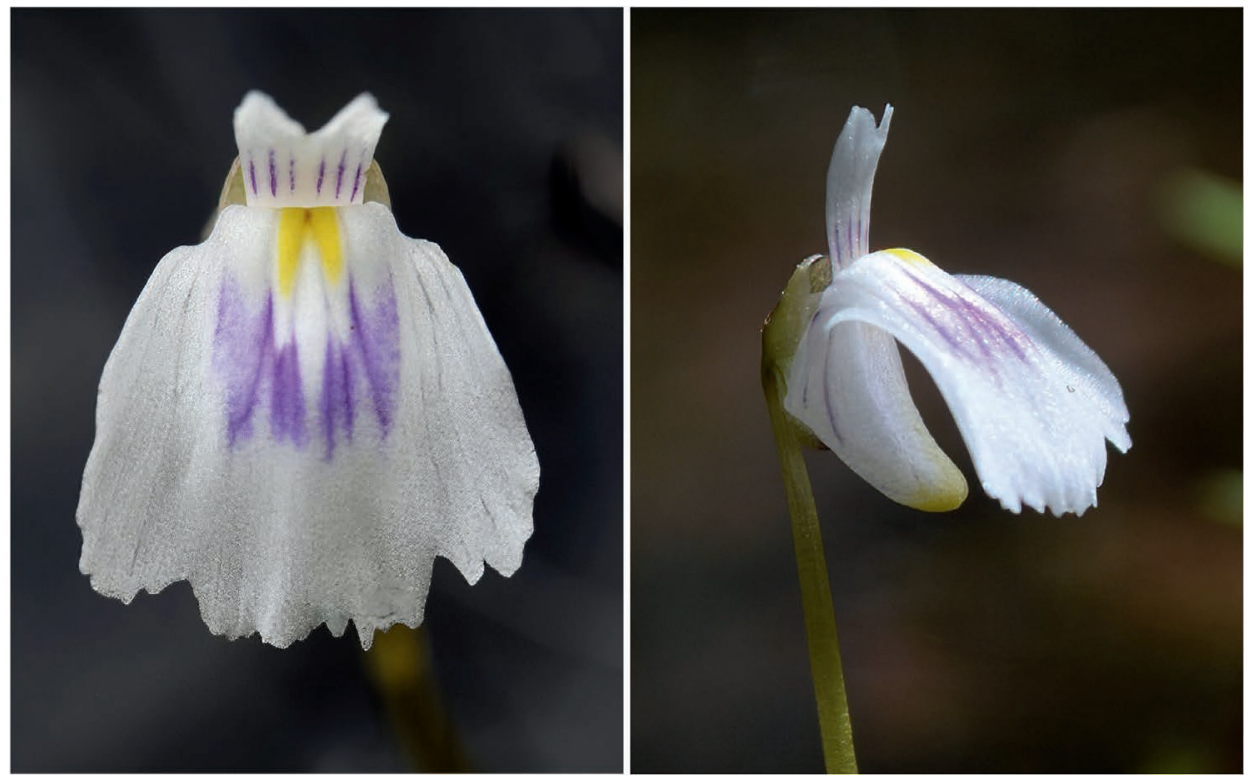

Figure 16: Utricularia hamata flower frontal view; flower lateral view (images T. Krueger). 
Utricularia limmenensis R.W.Jobson

Very small sized annual, terrestrial herb (Fig. 17). The specific epithet refers to the region within the catchment of the Limmen Bight River, from which Limmen National Park takes its name. Known from two collections in the Limmen Bight River catchment, Northern Territory. The two collection sites are located $\sim 50 \mathrm{~km}$ apart, one within Limmen National Park, and another located on private property. At both sites it is found on sandy clay substrate along the drying edge of Melaleuca dominated swamps. Similar to Utricularia albiflora R.Br. but differs in having a corolla pale violet, a narrow upper-lip limb slightly constricted near middle, corolla lower-lip limb strongly three-lobed, and spur long, cylindrical from base, curved towards apex, 1.3-2 times longer than lower lip.

\section{Utricularia lowriei R.W.Jobson 2013}

Small probably annual, terrestrial or affixed subaquatic herb (Fig. 18). The specific epithet honours botanist Allen Lowrie, who has greatly advanced the study of Drosera, Stylidium, and Utricularia. Found in far north Queensland on the Yorke Peninsula, in shallow water at edges of depressions on deep Sand. Endemic to a small area north of Cooktown, and also found c. $650 \mathrm{~km}$ further north at Sanamere Lagoon and Jacky Jacky. This species differs from Utricularia dunstaniae with presence of three filiform central lower lip lobes that are longer than the spur.

\section{Utricularia magna R.W.Jobson \& M.D.Barrett 2018}

Medium-sized probably annual, terrestrial herb (Fig. 19). The specific epithet is from the Latin magnus (big, great, large) and refers to the unusually large bladder-traps. Known only from the southern edge of Prince Regent Nature Reserve, where it is restricted to sandstone pavements. Similar to Utricularia tridactyla P.Taylor, but differs in having a light-mauve corolla, a shallowly 3-lobed corolla lower lip with lobes broadly rounded at the apex, corolla upper-lip superior part obovate, bladder-traps usually to c. $7.2 \mathrm{~mm}$ (rarely to $10 \mathrm{~mm}$ ) long. This species was also previously confused with $U$. arnhemica P.Taylor from the Northern Territory, based mainly on bladder-trap size.

\section{Utricularia oppositiflora $\mathrm{R}$.Br. 1810}

Terrestrial or subaquatic annual or perennial herb (Fig. 20). The specific epithet is from the Latin oppositus and flora, referring to the opposite pedicels and flowers that are often spaced 180 degrees at the same node on the inflorescence. Widely distributed from south-western Western Australia to coastal South Australia, Victoria, and New South Wales. In Western Australia, there are four known sites from Kalbarri, Perth, the Stirling Ranges, and Cape le Grand on the southern coast. In eastern Australia, Utricularia oppositiflora occurs from around Nabiac, New South Wales, southward to Wilsons Promontory, Victoria, Tasmania, and south-eastern South Australia. The species inhabits shallow seasonal swamps and depressions, and creek-lines in moist heathland. Bentham (1868) included U. oppositiflora collected in 1804 by Robert Brown near Sydney, New South Wales under U. dichotoma. This was accepted as a synonym by Taylor (1989). Jobson and Baleeiro (2020) resurrected this species based on molecular evidence. U. oppositiflora has been confused in the past with $U$. dichotoma. Although $U$. oppositiflora varies considerably in size (being mostly dependent on water depth), it is largely morphologically consistent, and is always characterised by dark-purple vertical nerves on the upper corolla lip and a broad, dorsi-ventrally compressed corolla spur that is shorter than the lower lip. 

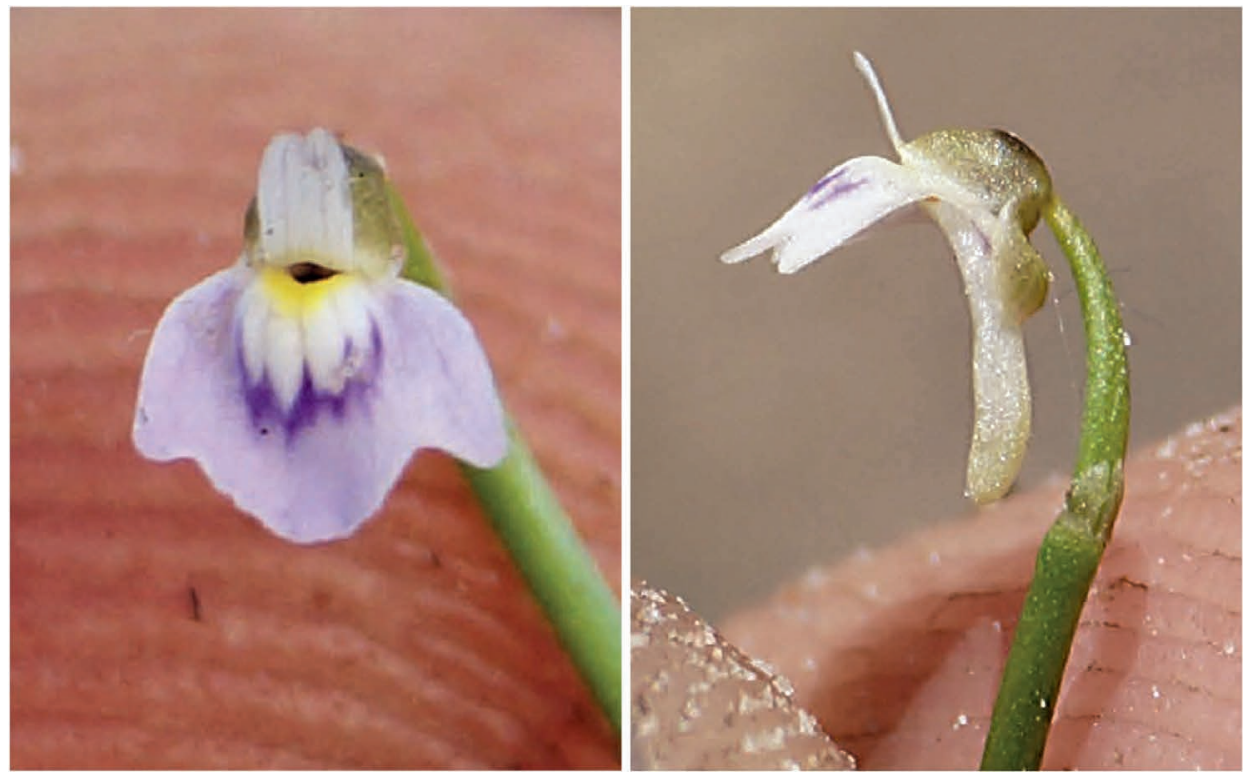

Figure 17: Utricularia limmenensis flower frontal view; flower lateral view (images by R.W. Jobson, courtesy of The Royal Botanic Gardens \& Domain Trust, Sydney).
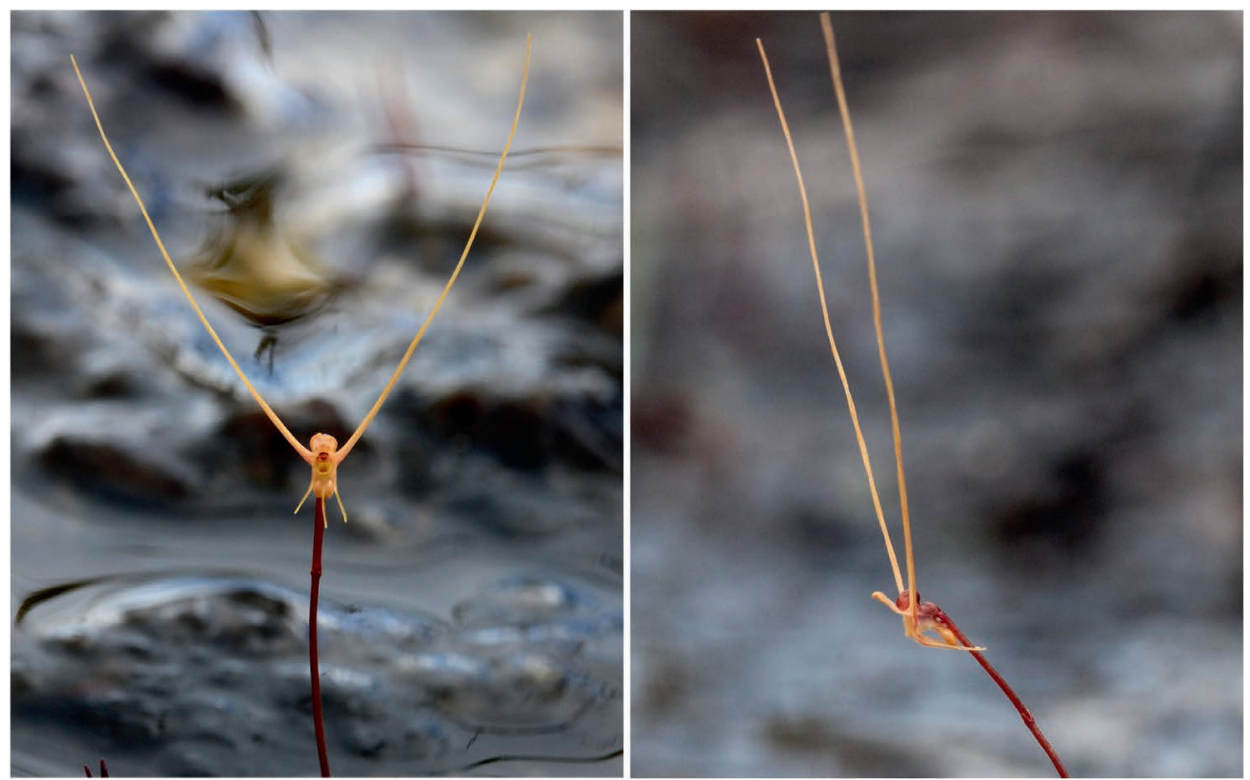

Figure 18: Utricularia lowriei flower frontal view (image R. Nunn); flower lateral view (image G. Bourke). 


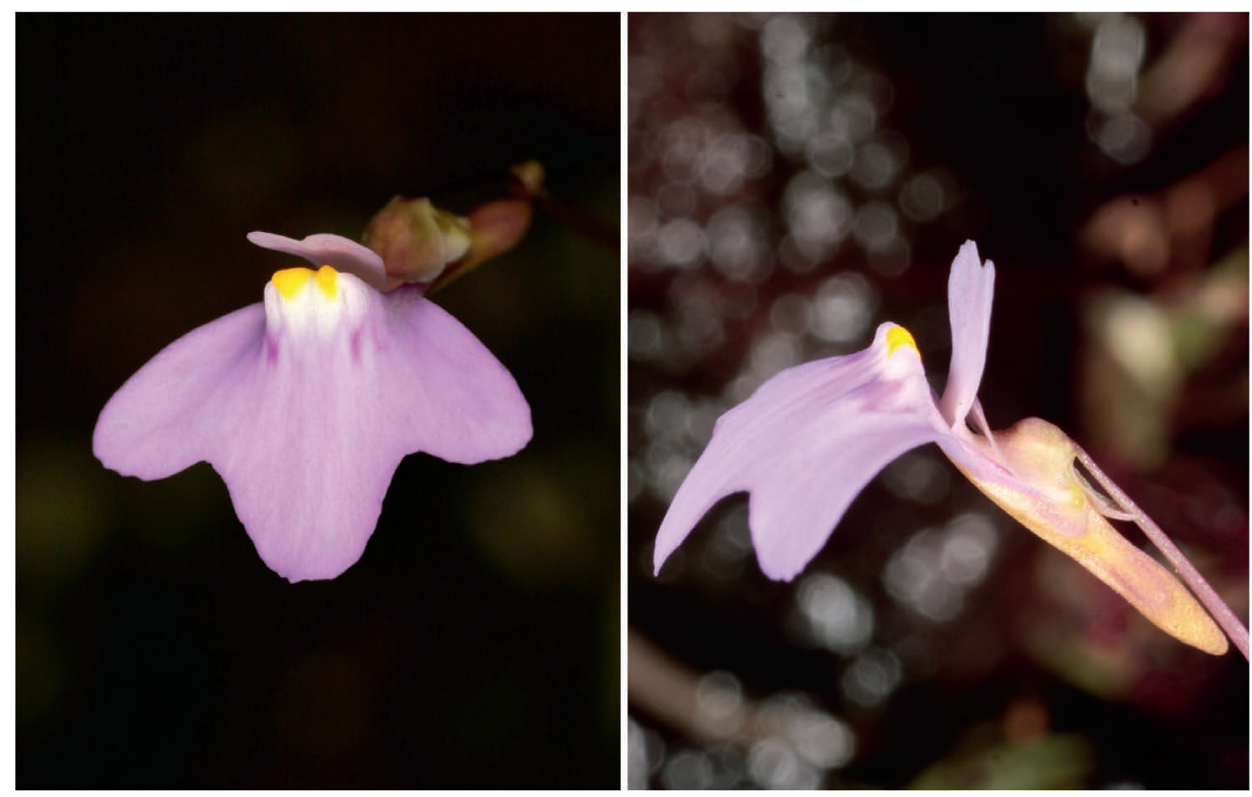

Figure 19: Utricularia magna flower frontal view; flower lateral view (images R. Barrett).

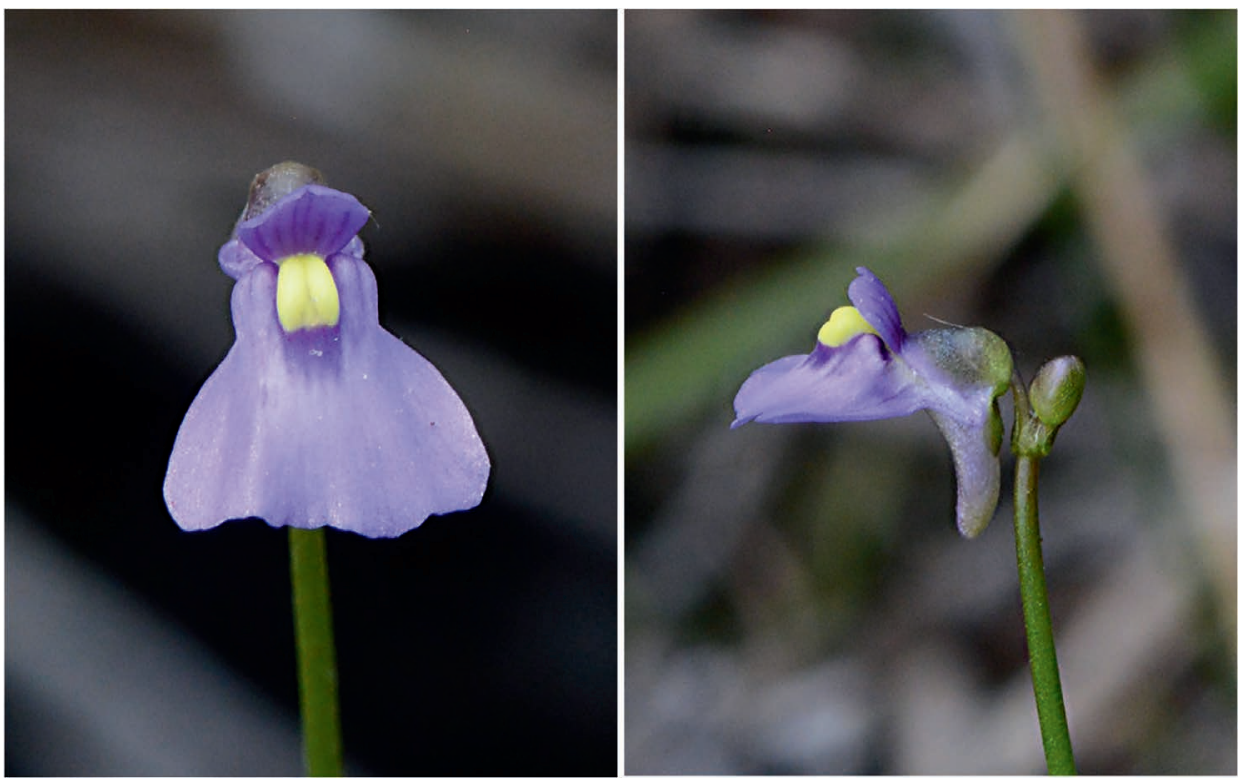

Figure 20: Utricularia oppositiflora flower frontal view; flower lateral view (images R. Nunn). 

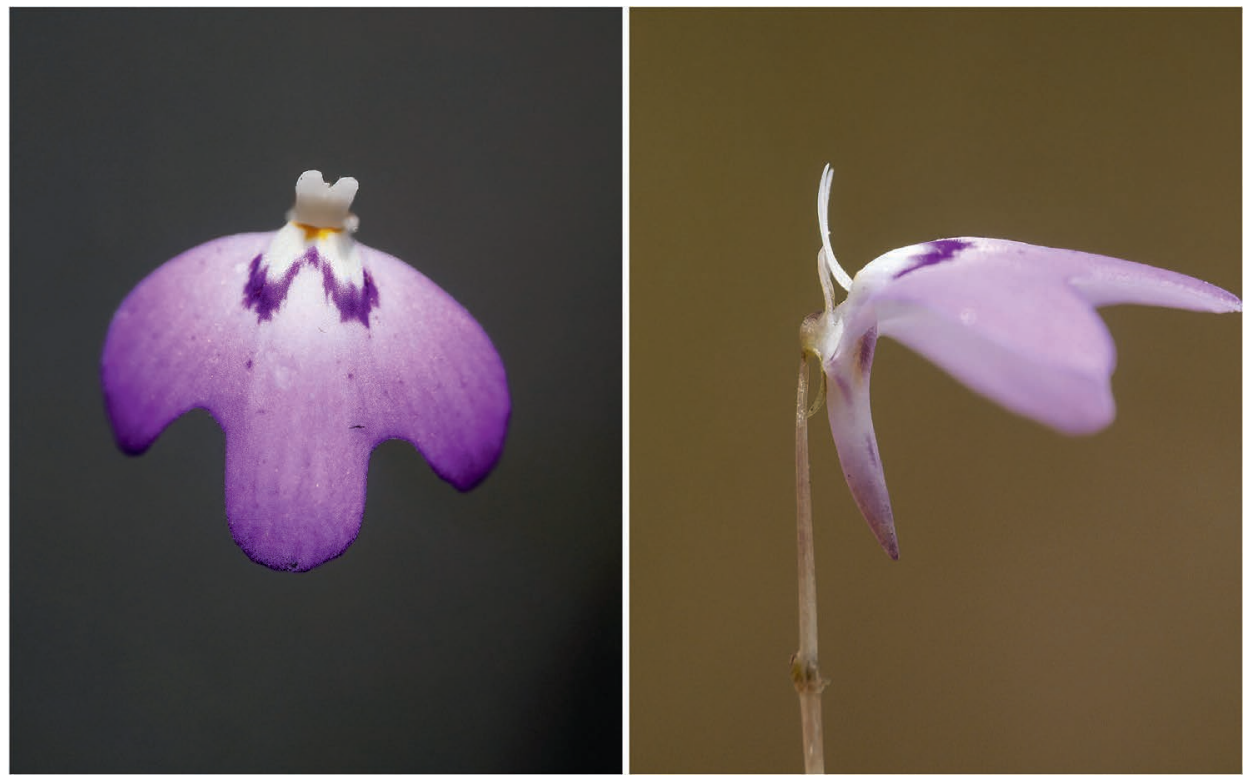

Figure 21: Utricularia papilliscapa flower frontal view; flower lateral view (images T. Krueger)

\section{Utricularia papilliscapa R.W.Jobson \& M.D.Barrett 2018}

Small-sized annual, terrestrial herb (Fig. 21). The specific epithet refers to the densely papillose peduncle base. Known only from a few locations in the Northern Kimberley region of Western Australia. Found on shallowly inundated sandy skeletal substrate over sandstone pavement. Similar to Utricularia tridactyla but differs in having lower peduncle densely papillose, a corolla light pink, a more shallowly 3-lobed lower lip with palate a yellow patch at base, corolla upper lip superior part oblong and acutely bifid.

\section{Utricularia speciosa $\mathrm{R}$.Br. 1810}

Subaquatic perennial herb (Fig. 22). The specific epithet is from the Latin speciosus meaning showy, splendid. Known from only four populations restricted to Wallum swamps and lagoons on the central and mid-northern coast of New South Wales. A subaquatic species often found in the deeper areas of swamps ( $\sim 50 \mathrm{~cm}$ deep) the large size of the multi-veined leaves may allow this species to occupy deep-water habitats. Bentham (1868) included Utricularia speciosa collected in 1804 by Robert Brown near Sydney, New South Wales under U. dichotoma. This was accepted as a synonym by Taylor (1989). Jobson and Baleeiro (2020) resurrected this species based on molecular evidence. Other than its habitat preferences, U. speciosa is distinguished by leaves that are obovate, apex rounded or truncate, $3-6 \mathrm{~cm}$ long, veins $2-13$ and an upper corolla lip that is bilobed.

\section{Utricularia wannanii $\mathrm{R}$.W.Jobson \& Baleeiro 2015}

Small sized probably annual, lithophytic herb (Fig. 23). The specific epithet honours Dr Bruce Wannan, botanist and environmental scientist at the Queensland Herbarium (BRI), and collector of Utricularia wannanii. Only known from the type location at Garimbu Creek, a tributary of the Roe River catchment, western Kimberley region. Found growing on seepage of shaded south fac- 


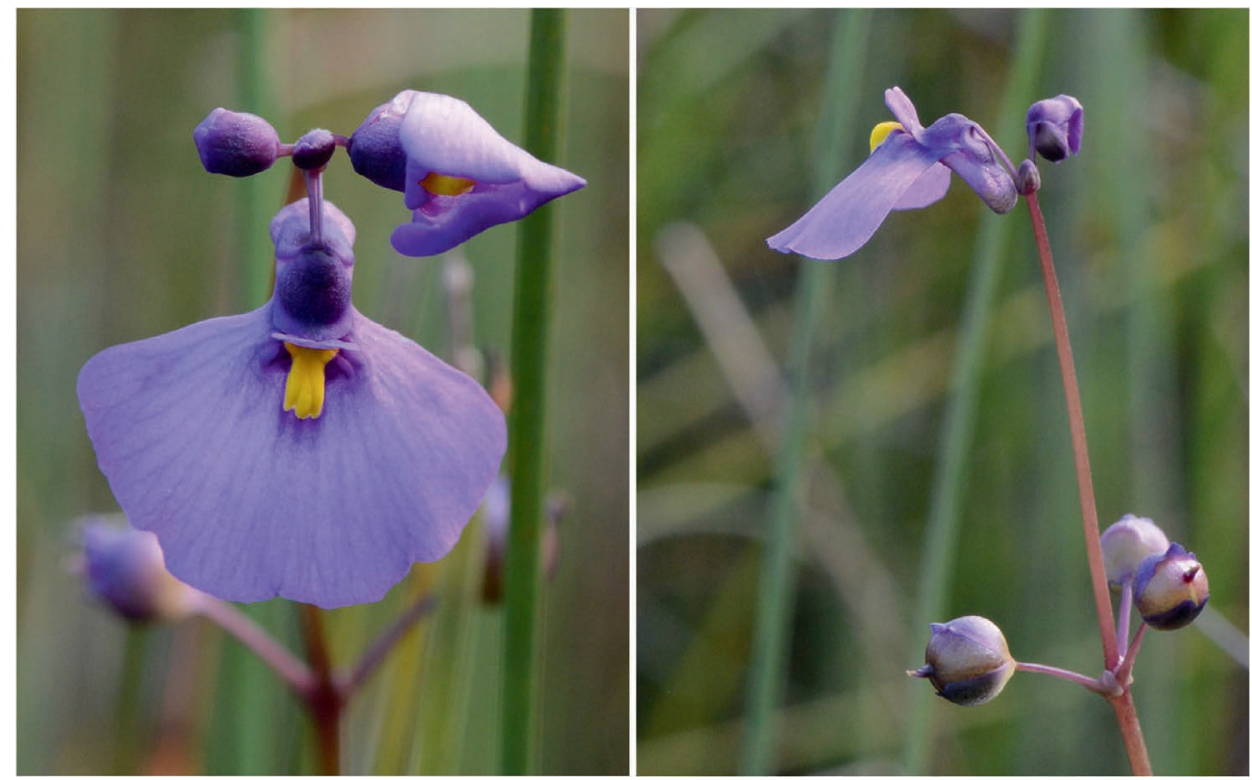

Figure 22: Utricularia speciosa flower frontal view; flower lateral view (images R. Nunn).

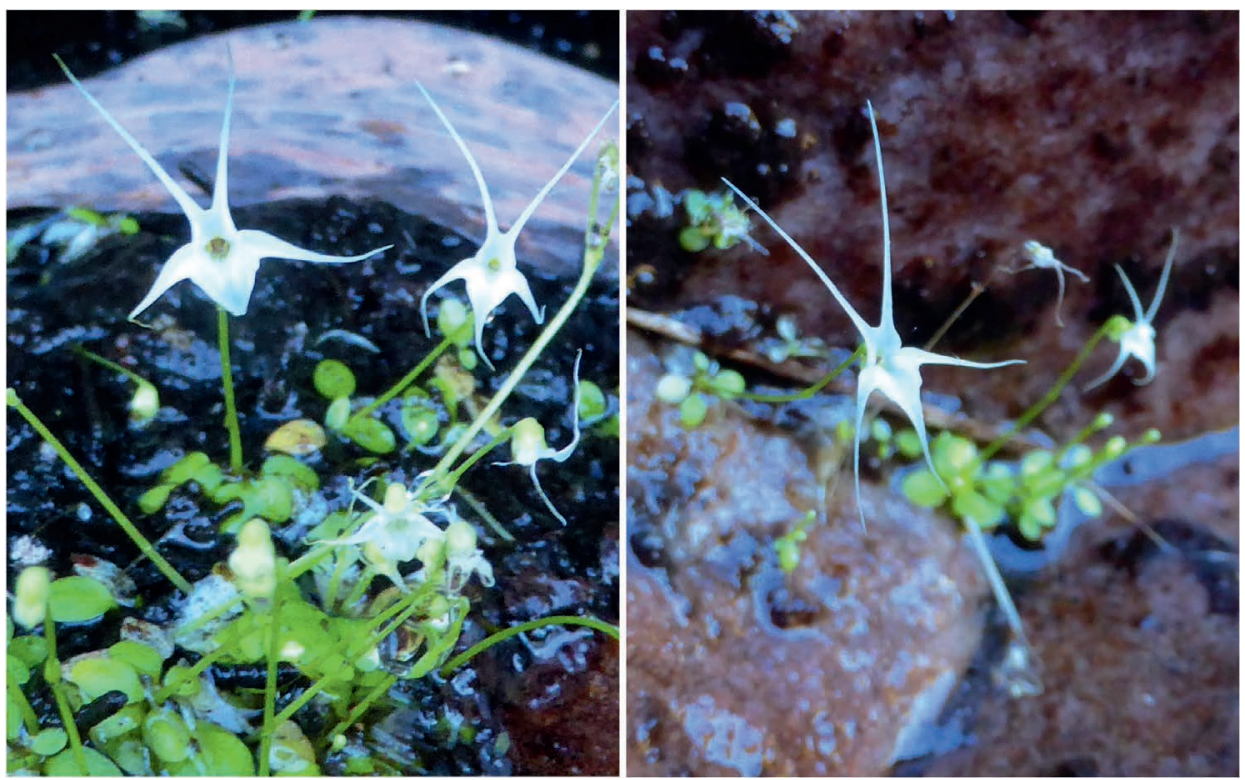

Figure 23: Utricularia wannanii flower frontal view; flower lateral view (images B. Wannan). 
ing sandstone rock-faces (vertical and horizontal) in the lithophytic habit, with nearby drier areas containing a Stylidium sp. With its lithophytic habit, small size, and uniquely shaped flowers, $U$. wannanii is unlikely to be confused with any other Australian species of Utricularia. Has bracts and bracteoles similar to those of $U$. georgei P.Taylor but differs in having corolla lobes of the upper and lower lip long, subulate, with strongly reduced spur, peduncle up to $15 \mathrm{~mm}$ long, seeds ovoid.

Acknowledgements: The author would like to thank the following for the kind use of their images, without which this paper would be incomplete. Russell Barrett, Greg Bourke, Darren Cullen, Richard Jobson, Thilo Krueger, and Bruce Wannan. Andreas Fleischmann and John Brittnacher are also thanked for their time and effort in proof reading and formatting this paper.

\section{References:}

Bentham, G. 1868. Flora Australiensis, vol. 4. Reeve: London.

Fleischmann, A. 2012. The new Utricularia species described since Peter Taylor's monograph. Carniv. Pl. Newslett. 41: 67-76.

Fleischmann, A. 2015. Taxonomic Utricularia news. Carniv. Pl. Newslett. 44(1): 13-16.

Jobson, R.W. 2013. Five new species of Utricularia (Lentibulariaceae) from Australia. Telopea 15: 127-142.

Jobson, R.W., and Baleeiro, P.C. 2015. Two new species of Utricularia (Lentibulariaceae) from the North West region of Western Australia. Telopea 18: 201-208.

Jobson, R.W., Baleeiro, P.C., and Barrett, M.D. 2018. Six new species of Utricularia (Lentibulariaceae) from Northern Australia. Telopea 21: 57-77.

Jobson, R.W., and Cherry, W. 2020. Utricularia gaagudju, a new species for the Northern Territory, and a recircumscription of $U$. kimberleyensis C.A.Gardner. Telopea 32: 61-68.

Jobson, R.W., and Davies-Colley, T. 2020. Redescription of the suspended aquatic Utricularia aurea Lour. (sect. Utricularia) and a new species U. adamsii for northern Australia. Telopea 23: 21-33.

Jobson, R.W., and Baleeiro, P.C. 2020. Radiations of fairy-aprons (Utricularia dichotoma, Lentibulariaceae) in Australia and New Zealand: molecular evidence and proposal of new subspecies. Aust. Syst. Bot. 33: 278-310.

Lowrie, A. 2014. Carnivorous Plants of Australia Magnum Opus, Vol. 1- 3. Redfern Natural History, Dorset.

Müller, K., and Borsch, T. 2005. Phylogenetics of Utricularia (Lentibulariaceae) and molecular evolution of the $\operatorname{trn} \mathrm{K}$ intron in a lineage with high substitutional rates. Plant Syst. Evol. 250: 39-67.

Taylor, P. 1989. The genus Utricularia. Kew Bulletin Additional Series XIV. HMSO: London. 


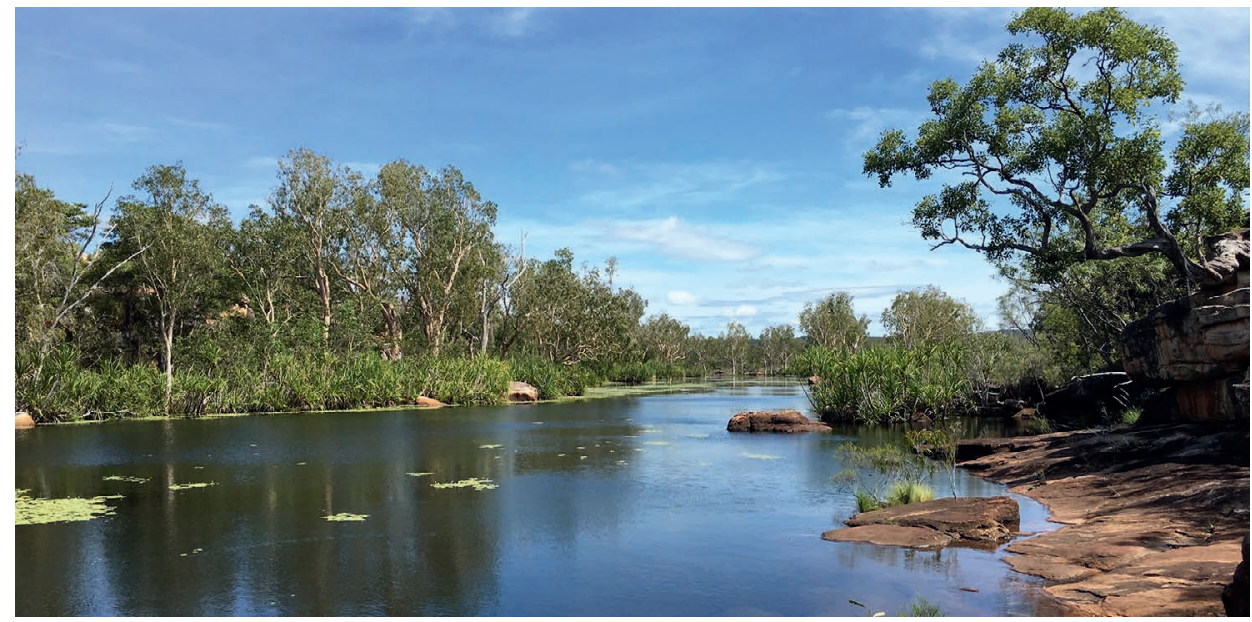

Figure 24: Habitat of Utricularia albertiana, Theda Station, WA, Australia. Photo by Richard Nunn.

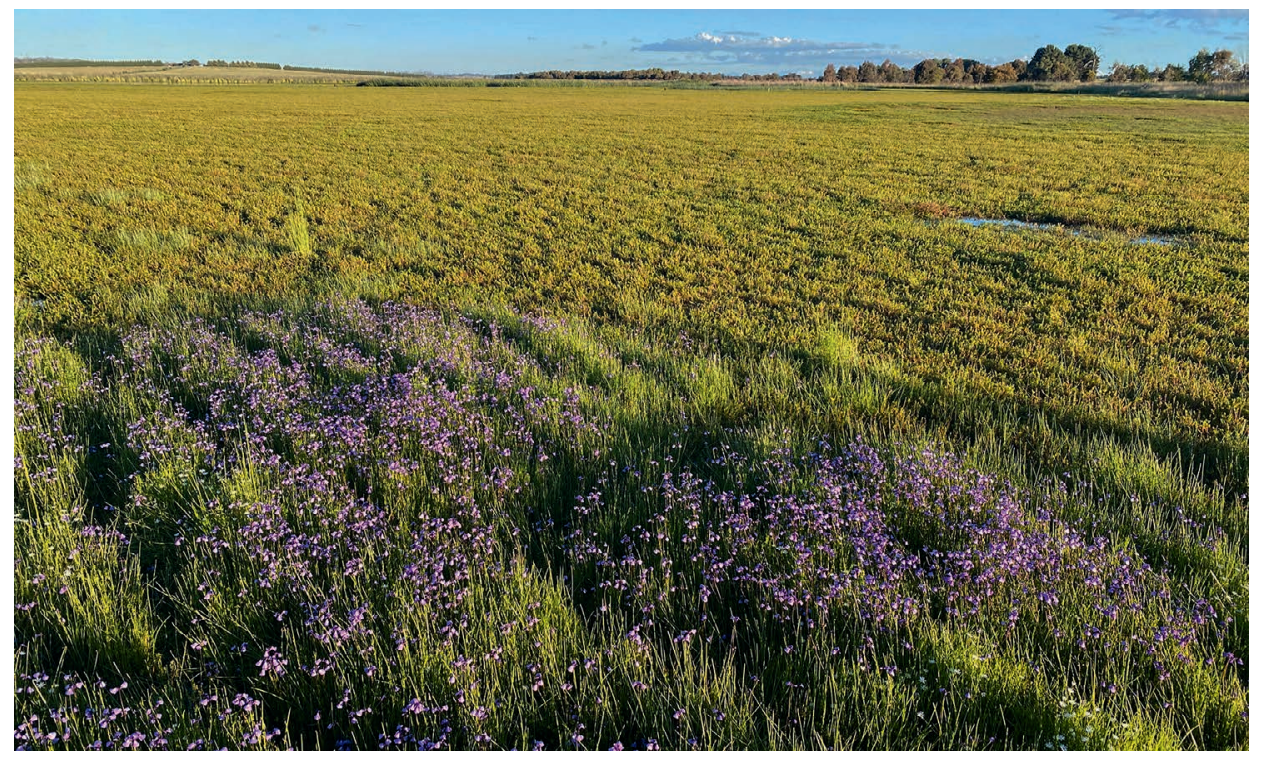

Figure 25: Habitat of Utricularia dichotoma subsp. novae-angliae, Arding, NSW, Australia. Photo by Richard Nunn. 